\title{
The Private Tutorial Policy under the Framework of Multiple Institutional Logics Analysis and Its Enlightenment
}

\author{
Zhang Chenchen \\ Beijing Normal University, China
}

\begin{abstract}
Based on the Multi-Institutional Logics Analysis Framework, this paper defines the main bodies involved in Chinese extra-curricular tutoring as the government, market, school and family, and analyzes their influencing factors of the policy of extracurricular tutoring under the four-tier system logic of government, market, school and family. The government aim to ensure the quality of education and student development, and to maintain social stability Parents and students, as demanders, regard extra-curricular tutoring as a choice of service, while suppliers form a disorder under the logic of efficiency and profit stimulation. Families adopt to extracurricular tutoring as means of achieving class reproduction, and students regard extracurricular tutoring as a support strategy for higher education. Finally, the author thinks that in the formulation and implementation of relevant policies concerning extra-curricular tutoring, it is necessary to ensure that education "blossoms" can be guaranteed from the macro and micro perspectives, and at the same time, all participants involved in extra-curricular tutoring should be orderly guided to regulate the market chaos, seek advantages and avoid disadvantages, so as to promote consumers and to lead families in making rational choices for extracurricular tutoring as well.
\end{abstract}

\section{Introduction}

From 2017 to 2018, Chinese government has stepped up its efforts to govern private tutoring institutions, and has issued the Opinions on Deepening the Reform of the Educational System and Mechanism, pointing out that it is necessary to "standardize extracurricular education and training institutions, strictly examine the qualifications of running schools"; and to issue the "Special Governance on Reducing the Burden of Primary and Secondary School Students Extra-curricular Training Institutions". The notice of action is to conduct a "thorough investigation, comprehensive rectification, supervision and inspection" of the off-campus training institutions. The special rectification for tutoring institutions at the national level originated from the crazy growth of off-campus tutoring in recent years. According to the "Survey Report on the
Status of Teachers in China's Counseling and Education Industry and Counseling Institutions" issued by the Chinese Education Association, in 2016 there were 180 million primary and secondary school students, more than 137 million extracurricular counseling students in primary and secondary schools, and the market value for extracurricular tutoring exceeded 800 billion RMB.

The phenomenon of extracurricular cram education does not constitute a public policy problem. However, some of the problems that affect students' development in private tutoring should be included in the government's educational policy. What are the reasons behind the crazy growth of extracurricular cram? What are the key factors? What is the logic of related subjects? What is the effectiveness of the newly issued normative policies in implementation? Can the current policy initiatives be further refined?

This article mainly discusses the private tutoring services, such as paid tutoring provided by individuals, institutions and other groups. The private tutoring discussed in this paper only refers to the primary, junior and senior middle school stages, not involving pre-school, higher education, and vocational education.

There are three sources of data in this study. First, archives, including policy documents issued by the Central Government and the Ministry of Education. Second, academic literature such as papers and monograph. Third, the field survey through the email, telephone, and field visits to HR departments in more than 10 famous tutorial institutions located in Beijing, on their recruitment of teachers.

\section{The Process of Institutionalization of Remedial Education}

Park et al. [7] divided tutorial education into private supplementary and public supplementary education. M. Bray and G. Weiyu [6] divided the tutoring mode into one-to-one tutoring, small class, large class and online learning. This paper combines the two classification methods to form a conceptual framework.

Dhall [1] concluded that policies for extracurricular tutoring include education policy and 
business policy. Bray and Lykins [5] argued that most countries have strict regulations on the registration of remedial institutions, but little attention has been paid to the qualifications of remedial instructors. For in-service teachers to participate in extra-curricular tutoring, the main types of policy include prohibitive policy, nonencouragement policy, licensing approval policy, and non-intervention policy. Pai [8] divided the policy response of private tutoring into five types: strict prohibition, mixed policy, cognitive supervision policy, laissez-faire policy and active encouragement policy. Kwok [4] argues that Chinese government forbids and punishes teachers and principals who participate in private tutoring, whereas implements a policy of tolerance for tutoring in private market. Lin and Changwen [10] divided the governance policy of extracurricular remediation into the "nonintervention" policy stage before the end of the 20th century and the "mixed prohibition and norms" policy in the 21 st century.

China currently has adopted a prohibitive policy for mainstream schools and their teachers, whereas the government has neither encouraged nor prohibited the extra-curricular tutoring activities of institutions outside the mainstream schools, just regulating them. This features a dual administration to "inside-the-public system" and "outside-the-public system". Under this dual system, we can not rule out that mainstream school teachers still participate in paid tutoring outside schools, jumping outside the school walls.

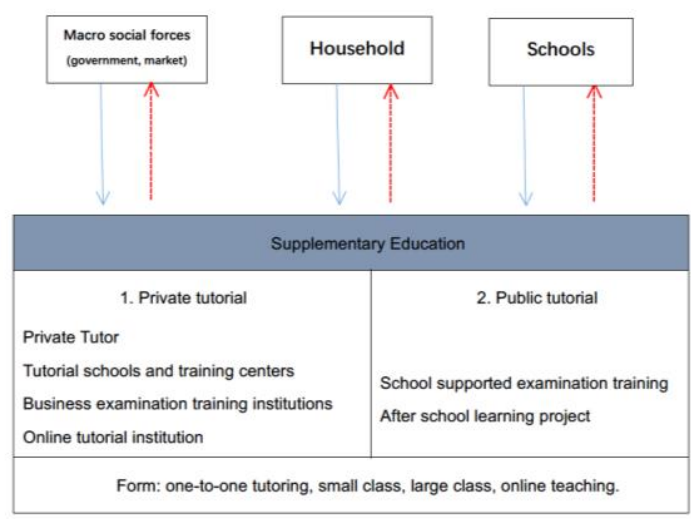

Figure 1. Analysis framework

Fuwei [9] applies multiple institutional logics in analyzing independent institution dilemma which is owed to the dynamic interplay of state, market, family and education. Likewise, this article will analyze within the framework of multiple institutional logics. The development and reform of extra-curricular tutoring will be influenced by four levels of institutional logic: government, market, school and family. The first two belong to the macro level, and the latter two belong to the micro-subject.
The logical relationship between these four subjects and extracurricular tutoring is shown in Figure 1.

\section{The Logic of the Government}

\subsection{Ensure the Quality of Education and Student Development}

The government has an obligation to ensure that its citizens have a good education in public schools, which means that there must be mechanisms to ensure that the best teachers, facilities and teaching materials are provided to students within the limits of funds. In the field of private education, the same principle applies, and methods of supervision and control are needed to ensure the highest quality of public and private education.

In recent years, "super-curriculum teaching", " premature " and "examination-oriented tutorial" are common in cram schools, and these behaviors violate the laws of education and hamper the growth and development of adolescents by increasing the burden of students and families. These negative problems must be regulated only by the government.

\subsection{Safeguarding Education Equality and Maintaining Social Stability}

The mainstream school education has the shortcomings in terms of duration, curriculum types and training methods. To guarantee the quality and equity of education, and to diversify the ways of personnel training, Chinese government allows extracurricular remedial education to coexist with mainstream school education.

However, extra-curricular tutoring institutions inappropriately provide teaching with high tuition fee, artificially intensifying the competition among students, and bringing economic burden to families. This has stroke the pace of school system and has a negative impact on social stability. Therefore, the government is obliged to regulate extracurricular tutoring.

\section{Market Logic}

The basic principles of the market are efficiency and profitability. The main body of the market is divided into supply side and demand side.

\subsection{The Demand Side - Students and Parents}

Parents believe that tutoring is an educational service that can be freely traded, because families are free to choose a tutor or a subject, or to choose different type, length of class and intensity of tutoring, which can not be realized in the public schools. Families' demand for extra-curricular 
tutoring is influenced by many factors, including macro, institutional and micro ones.

\section{i. Macro Level}

Family demand for extra-curricular tutoring is influenced by economic development, educational structure, cultural values, and government policies.

First, with the rapid growth of China's whole economy, household income has generally increased and families have solid economic basis to purchase remedial services.

Second, the government lift the ban on private education after the Reform and Opening-up, and private tutoring become widely accepted by the whole society.

Third, Chinese College Entrance Examination has become the best and most important way for social strata to move upward. The Elementary School Entrance Examination and the Secondary School Entrance Examination are actually preparation system for the former one. On these selective examinations, the content usually goes beyond the scope of regular schools, thus arousing the family's demand for supplementary study and training outside school. Every family are fearing of losing advantages in the College Entrance Examination competition, and thus choose private remedial education as insurance investment.

Last but not least, Chinese culture emphasizes the selection of elites through diligent study and examination, such as the traditional concepts of "foolish birds fly first", "iron pestles grind into needles" and " A good scholar will make an official". Students are encouraged to pay more to improve their academic performance by participating in extracurricular remedial classes and prolonging their learning time.

\section{ii. Institutional Level}

At the institutional level, demand can be driven by schools.

Firstly, most schools are characterized by low teacher-student ratio, large class size, teachers' heavy teaching task is, long class, and emphasis on examination-taking skills which cause insufficient academic input, insufficient attention to students' personal development, and low quality of schools teaching, leading to the demand for private tutoring.

Secondly, the Burden Reduction Policy forbid schools to organize tutoring, assign too much homework or prolong the study time in schools.

As a result, families turns to the tutoring institutions outside schools, and tutoring companies absorb most of the expenditure of family tutoring.

\section{iii. Micro Level}

At the micro level, the pressure of tutoring comes from peer pressure brought by successful and superior students participating in tutoring.

In Asia, especially in China, students receiving remedial education are not only those with poor grades, but also those with high scores. Whether students take part in remedial education for the purpose of "cultivating excellence" or "filling up deficiencies", peer pressure will be brought to students with similar academic achievementsworrying about being inferior in competition; the social atmosphere of parental comparison and anxiety further aggravate this pressure, resulting in the "herd effect" of remedial demand and follow-up strategies, even in families that would not have remedial education. Therefore, they are also willing to participate in tutoring, which further enlarge the demand for tutoring.

\subsection{Supplier Factors}

\section{i. Tutorial Institutions}

For tutorial institutions, the logic they follow is profitability and efficiency.

Karl Marx once vividly described the profitseeking nature of capital: "Once there is a proper profit, capital will be bold. If there is $10 \%$ profit, it will be guaranteed to be used everywhere; if there is $20 \%$ profit, it will be active; if there is $50 \%$ profit, he will take risks; for $100 \%$ profit, it will dare to trample all human laws; if there is $300 \%$ profit, it will dare to commit any crime or even risk hanging its head." Driven by market demand, tutorial institutions have developed into efficient and easyto-replicate chains, and some have even developed into listed companies and international chains.

On the one hand, tutorial companies are driven by a profit-seeking and adopt quality-improving mode of operation, chain operation, and promotion of "star teachers", causing exaggerated publicity and high fees.

On the other hand, with the low barrier to admission of instructors, violations of the behavior of on-the-job tutors are widespread. These chaos and contradictions make the normative mechanism of the government necessary.

\section{ii. In-Service Teachers}

In-service teachers, whose salary is relatively at a low level, secretly take part-time position as tutors in cram schools. In a society that values knowledge and authority, teachers themselves are respected and famous in-service teachers are highly trusted by parents, which is the main reason for in-service teachers' special popularity as tutors. 


\section{Logic of Mainstream Schools}

Schools are confronted with the dilemma whether tutorial institutions play a complementary or a substitute role in school education.

\subsection{Complementary Effect}

Private tutoring can exert a complementary effect on mainstream school education by sharing teachers' tasks, cultivating high-quality students (even in violation of regulations), and promoting the diversity of personnel training.

The Education Department has issued a series of "burden reduction" policies and measures, such as prohibiting primary and secondary schools from issuing reference materials and various exercise books, controlling the amount of homework, streamlining curriculum, reducing curriculum standards, and controlling all kinds of competition activities.

However, because the specific policy measures are mainly aimed at schools and research institutes, there is no binding force on the off-campus parts, leading to a strange picture in which primary and secondary schools fall into the school burden reduction while the off-campus training institutes desperately add codes. For example, the "elementary entrance examination" cancelled schools has been operated underground or semi-underground, eventually leading to the continuing prosperity of off-campus training classes and students overburden.

In addition, the "premature education" and "cherry-picking selection" carried out in extracurricular tutoring perfectly match with the "topnotch enrollment" appeal of some schools, and the high-quality educational resources represented by key schools provide a premium resource for the enrollment of tutoring institutions.

\subsection{Substitute Effect}

Tutorial companies could have a substitute effect on mainstream schools.

Firstly, school teachers will take part-time job in tutoring institutions and neglect school teaching. When teachers provide private remedies for their students, they may reduce the regular courses and concentrate more on private remedial courses, because these courses are much more expensive than the regular courses taught in the mainstream schools.

Meanwhile, students' attitude to school teacher will change, resulting in the alienation of families from schools and teachers. Students are more likely to respect remedial teachers and alienate school teachers because of their poorly trained subject by turning to remedial teachers for help.
It can be seen that in school logic, extra-curricular tutoring can supplement the mainstream schools, absorb teaching tasks and teachers, cultivate highquality students (even in violation of regulations), promote the diversity of personnel training, at the same time, it also has the role of "substitution" for school education, resulting in the alienation of families from schools and teachers. It not only has negative effects, such as overweight schoolwork, over-class teaching and premature remediation, but also has positive effects, such as diversification of personnel training. The relationship between them is complex. In fact, these phenomena are inevitable phenomena in education, but schools are subject to more administrative regulations and transfer part of the difficult tasks and contradictions, which are absorbed in extra-curricular tutoring.

\section{Family Logic}

\subsection{Confucian Values}

Chinese families are deeply influenced by Confucian values. The basic assumption of parents is that the more families invest in their children's studies, the greater their children's academic achievements will be, and their academic success will determine their future career development. In addition, Confucianism attaches great importance to hierarchy and filial piety. Chinese children regard compliance with their parents' expectations as a virtue, and therefore tend to follow their parents' arrangements.

A minority number of families taking private tutoring will generate peer pressure to other families, which can result in a Blind Herd Effect. Obedient Chinese children's logic is to follow their parents' arrangements, participate in tutoring, study hard, and try their best to achieve higher academic achievement.

\subsection{Socio-Economic Status}

Factors such as parents' educational level, social and economic status and family size influence families' inclination to taking remedial courses. For families, the higher the educational level of parents, the higher the social and economic status, and the fewer family children, the greater probability of students participating in extra-curricular tutoring.

In order to maintain competitive advantage, the dominant stratum pays more and more attention to shadow education as an invisible barrier to exclude the disadvantaged class and to realize the intergenerational inheritance of family capital. Students from higher socio-economic status families have more capital to get high-quality after-school counseling and school learning. 
Remedial education resources show a trend of gathering students with better socio-economic background in developed areas, large and medium cities and families.

\subsection{Guarantee Strategy}

Students tend to take extra-curricular tutoring as a guarantee strategy for further education. Studies by Wei and Bray [11] show that students' learning expectations are significantly correlated with their participation in extra-curricular remedial courses. Compared with students who intend to find employment immediately after graduation, those who aim to enter key high schools are more likely to accept remedial courses.

It can be concluded that the reformed examination selection system featuring with flexible examination topics, making students' academic competition fiercer. Under the exaggerated propaganda of extracurricular tutoring institutions and peers pressure, parents and students adopting to extracurricular tutoring as a safeguard mechanism to maintain social and economic status and to promote the upward mobility of strata, influx into tutoring organizations.

\section{Discussion}

Reform of schools' enrollment and examination system featuring flexibility of examination questions, and arousing the anxiety of parents and students. Extra-curricular tutoring thus exists as a safeguard mechanism of maintaining socio-economic status and promoting upward class mobility. Even if the policy explicitly prohibits in-service-teachers' extracurricular tutoring, these behaviors may turn into underground or semi-underground behavior, or other forms of operation, stimulating by the huge demand in the market.

With the reform of the examination enrollment system, the continuous growth of family income and the continuing implementation of the School Burden Reduction Policy, a strong and increasing demand for extra-curricular tutoring will resume. Four ministries and commissions have cooperatively standardized extra-curricular tutoring, requiring it to "handle relevant certificates in accordance with regulations according to law", which can restrict the illegal operation of extra-curricular tutoring institutions. However, families have "extra-curricular teaching" and "pre-teaching". There is a great demand for such bad behaviors as strengthening examination-taking, which may turn into underground or semi-underground behavior or operate in other forms even if the policy is explicitly prohibited.

To some extent, it can limit the "collusion" between tutoring institutions, schools and teachers by standardizing them at the same time. Relevant evaluation mechanism and accountability mechanism are complementary.

\section{Conclusion}

At present, at the macro level, it is necessary to insist on the registration supervision of a certain size of institutions. The government should set a cap on the tuition fees and supervise private tuition instead of prohibiting it. At the meso and micro levels, the government should promote the balanced development of education by supporting low-level schools and schools in poverty-stricken areas. Finally, schools need to guide family education so as to provide guidance for their rational investment.

\section{References}

[1] Dhall M., Trends and issues with private tuition: A global perspective. NTA Newsletter

(National Tutoring Association, USA), 2011 Winter (1), 515.

[2] H. Hao, Over 800 Billion Yuan of Extra-Curricular Tutoring Money was Paid by Primary and Secondary Schools Students Families in China in 2016. China Education Daily, 2016-12-28 (003). [in Chinese]

[3] K. Marx, Engels, Complete Works of Marx and Engels. People's Publishing House, 1972. [in Chinese]

[4] Kwok Y., Demand Intensity, Market Parameters and Policy Responses Towards Demand and Supply of Private Supplementary Tutoring in China[J]. Asia Pacific Education Review. 2010, 11(1): 49-58.

[5] M. Bray and C. Lykins, Shadow education: Private Supplementary Tutoring and Its Implications for Policy Makers in Asia. Asian Developing Bank \& Comparative Education Research Center, 2012.

[6] M. Bray and G. Weiyu, Regulating Private Tutoring for Public Good: Policy Options for Supplementary Education in Asia. International Review of Education, 2016: 62(2), 239-241. [in Chinese]

[7] Park H., Buchmann C., Choi J. and Merry J., Learning beyond the School Walls: Trends and Implications. Annual Review of Sociology, 2016: 42(1).

[8] P. Pai, "Shadow Education": Research and Enlightenment on Extracurricular Tuition in Foreign Countries. Foreign Primary and Secondary Education, 2007 (09): 44-48.

[9] W. Fuwei, The Dilemma of Institutionalization of Independent College: Policy Change Shaped by Multiple Institutional Logics. Peking University Education Review. 2012,10(02):79-96+189-190. [in Chinese]

[10] Z. Lin and Z. Changwen, Evolution and Enlightenment of Korean Shadow Education Governance 
Policy. Foreign Education Research, 2017 (05): 66-76. [in Chinese]

[11] Z. Wei and M. Bray, Influencing factors of shadow education and its policy significance - Take Chongqing as an example. Educational Science Research, 2017 (06): 5662. [in Chinese]. 